\title{
Psychotherapy Ethics in Twentieth-Century Literature a
}

\author{
Anna Magdalena Elsner \\ The Oxford Handbook of Psychotherapy Ethics \\ Edited by Manuel Trachsel, Jens Gaab, Nikola Biller-Andorno, Şerife Tekin, and John Z. Sadler \\ Subject: Philosophy, Philosophy of Mind Online Publication Date: Sep 2020 \\ DOI: $10.1093 /$ oxfordhb/9780198817338.013.88
}

\begin{abstract}
Keywords
Ethical issues arising in the practice of psychotherapy, such as confidentiality, boundaries in the therapeutic relationship, and informed consent, figure prominently in a range of twentieth-century literary texts that portray psychotherapy. This chapter analyzes the portrayal of these conflicts, but also stresses that they are often marginal to the overall plot structures of these narratives and that literary depictions of psychotherapy are often vague or even inaccurate concerning key characteristics of psychotherapeutic practice. Focusing on examples that either illustrate professionalism and the absence of ethical challenges in psychotherapy, or take up the ethical reservations that fueled anti-Freudianism or the anti-psychiatry movement, the chapter proposes that selected literary depictions of psychotherapy can play a key role in sensitizing therapists to the complex makeup of ethical dilemmas as well as illustrating the cultural and historical contexts of these dilemmas.
\end{abstract}

Keywords: psychotherapy, psychoanalysis, ethics, literature, ethical dilemma

\section{Introduction}

Psychotherapy, as a practice and as a profession, has fascinated literature since the advent of psychoanalysis. The topos of sharing dangerous emotions, dark family secrets, and compromising social taboos with a complete stranger has generated a multifaceted literary corpus in which this challenging situation has been explored in a range of genres. Ranging from the comical to the serious, these accounts have contributed to the widely popular image of a psychotherapeutic relationship in which personal and professional boundaries are often crossed. Against the background which the continuing legacy of Sigmund Freud and psychoanalytic theory constitutes for literature, the literary representation of psychotherapy, both as a topos and a process, has been duly noted by literary scholars (Berman 1985; Fust 1999). ${ }^{1}$ Few scholarly works, however, have focused on the 
ways in which these engage with specific ethical conflicts arising as part of psychotherapy.

Fictional representations of ethical conflicts and their role in the popular imagination have been described as "hold[ing] up a mirror" to the profession of psychotherapy (Gutheil and Brodsky 2008: 8). In order to explore these conflicts, the corpus of this chapter is restricted to literary texts that refer to professionally administered psychotherapy predominantly written in the latter half of the twentieth century, when psychotherapy became an increasingly popular mode of treatment. This time frame coincides with a general proliferation of what has been called the genre of the "illness narrative" or "pathography" (Hawkins 1993), namely autobiographical accounts of physical and mental illness written by patients, caregivers, and physicians. While the majority of the texts considered here might have autobiographical origins, the focus is not on authors who write by drawing on their experience either as patients or as therapists, but on those who "transform their selves into fictional alter egos" (Fust 1999: xiii). ${ }^{2}$ This entails the exclusion of a number of popular fiction and nonfiction subgenres, such as, for example, historical novels featuring Freud as a fictional character (Kohler 2014; Stone 1971; Yalom 1992) or the "psychotherapy tales" (Yalom 1989). ${ }^{3}$

It has to be acknowledged that within the wide range of literary works that address psychotherapy, this selection merely constitutes a representative sample, which should not create the misconceived impression that psychotherapy ethics constitutes a main focus of these works. While the documenting of the psychotherapeutic process or the exploration of the psychotherapeutic relationship may be key in the texts of several authors explored here, it frequently constitutes a merely marginal element in the overall plot structure of these novels, often only playing the role of satirizing or belittling the profession of psychotherapy. Despite being informed by a variety of therapeutic cultures and shaped by different literary movements, these texts share a number of features, such as the fact that they are either vague about specific schools of psychotherapy, or refer exclusively to (Freudian) psychoanalysis. They also often conflate psychotherapy with psychoanalysis and even psychiatry. While the portrayed patients highlight a more equal gender distribution, the majority of therapists in these texts are male. As such, the selection is unrepresentative of the field of psychotherapy, which, for example, has long been dominated by female practitioners (Lin et al. 2015). This calls for a specific framing when integrating these texts in a psychotherapy ethics curriculum, which ultimately raises larger claims about the interaction between literature, ethics, and medicine.

Literature and ethics have a long and complex relationship that is often dated as going back to Plato's expulsion of the poets from the ideal city in the Republic. More recent work on the intersection of literature and ethics has contested a narrow interpretation of Plato's view (Nussbaum 1990), with the field of narrative ethics arguing that literature can actively contribute to ethical understanding (Newton 1997). Building on this, advocates of "narrative medicine" have highlighted that literary texts can produce "narrative competence" by providing concrete examples of ethical conflicts, which strengthen "the ability to acknowledge, absorb, interpret, and act on the stories and plight of 
others" (Charon 2001: 1897). Yet, it has also been stressed that literary texts are not medical ethics cases, and that drawing on them in order to illustrate clearly definable ethical frameworks can constitute an instrumentalization or reduction of literature (Billington 2016: 113). In considering these ethical conflicts in literature, our reading should therefore not have "explicit end-points," it should aim to be "useful but not instrumental, resonant but not pious or didactic" (Billington 2016: 136). In the light of this, the following focus on confidentiality, therapeutic boundaries, professionalism, and informed consent, as well as the ethical conflicts foregrounded in the critiques of anti-Freudianism and antipsychiatry, aims also to sensitize to features seemingly beyond, yet integral to the ethics of psychotherapy, namely that these ethical conflicts have emerged in specific cultural, intellectual, political, and historical contexts. As such, the literary documenting of psychotherapy may contribute to highlighting the wider "societal impact" of ethical debates in psychotherapy (Marks 2017: 3).

\section{Confidentiality}

Freud's emphasis on full disclosure as constituting the cornerstone of psychotherapy (Freud 1964: 134) implies that "one of the most important ways that a patient must trust a therapist is to be convinced that what is spoken in the consulting room will stay in the consulting room" (Mosher and Berman 2015: 2). But maintaining confidentiality can be challenging for the therapist, which explains why the breach of confidentiality is a central theme in a number of literary works engaging with psychotherapy. Confidentiality is of particular importance in Zeno's Conscience (1923), Italo Svevo's comic novel of psychological realism. The text documents the self-analysis of Zeno Cosini, a businessman from Trieste, who initially starts therapy in order to stop smoking and who has been advised by his analyst to write an account of his early life. It soon becomes clear-because Zeno explicitly states that his fantastical account is unreliable-that Zeno constructs the story of his life as resistance to analysis. While Zeno's actual analysis is only discussed in the margin of the text, the novel's preface, supposedly written by Zeno's analyst, the anonymous Dr. S., highlights that the ethical consequences of a breach of confidentiality are key to Zeno's Conscience.

Dr. S. writes in the preface: "I am the doctor occasionally mentioned in this story, in unflattering terms. Anyone familiar with psychoanalysis knows how to assess the patient's obvious hostility toward me" (Svevo 2003: 3). The analyst not only apologizes for having asked his patient to write his autobiography, but also states that he resorted to publishing it out of "revenge," hoping that his patient will be "displeased" (Svevo 2003: 3), but agreeing to share the profits with Zeno if he resumes analysis. This emphasizes not only a problematic countertransference, but also exemplifies a breach of confidentiality not on the basis of supposed self-harm, but because of mutual antipathy. Fust has therefore pointed out that "this proviso totally subverts the idea of the therapeutic alliance, basic to any form of psychotherapy, into a commercial partnership to reap the profits of a disreputable venture" (Fust 1999: 73). 
A breach of confidentiality also provides the entry to Philip Roth's Portnoy's

Complaint(1969), which, as Berman put it, is not only "Roth's most celebrated psychoanalytic monologue but the novel which brought the analytic couch into the living rooms of millions of American families" (Berman 1985: 243). The novel has been described as "the most spectacular attempt at Freudian fiction in recent American literature" (Shechner 2003: 122), which established Roth as the author of psychoanalysis par excellence.

Alexander Portnoy, the narrator of Portnoy's Complaint, is a neurotic 33-year-old Jewish lawyer from New York, who turns to psychoanalysis in order to overcome his personal crisis that manifests itself in a number of physical symptoms (sexual impotence with Jewish women) and depression. Portnoy is well-versed in Freudian concepts and off-handedly cites the European literary canon while discussing his relationship with his parents, his low self-esteem, narcissism and anger. Preceding his monologue of sexual confessions, which ends with his therapist's, Dr. Spielvogel's, poignant remark "Now vee may perhaps to begin. Yes?" (Roth 1969: 274) is a short encyclopedia-like entry. This gives a pathological definition of "Portnoy's complaint" as "a disorder in which strongly-felt ethical and altruistic impulses are perpetually warring with extreme sexual longings, often of a perverse nature" (Roth 1969: 1), which have been described in a supposed article by Dr. Spielvogel entitled "The Puzzled Penis" published in Internationale Zeitschrift für Psychoanalyse. While this breach of confidentiality frames Portnoy's Complaint, its ethical implications are never discussed directly in the book itself given that Portnoy's therapy supposedly only begins once the book ends.

Berman has remarked that compared to other fictionalized therapists, the uniqueness of Roth's therapists generally "derives from their professional authenticity" (1985: 239). Even if, as Martin Tucker has observed, Dr. Spielvogel is an "ironic and paradoxically lovely portrait of a venerable Viennese father-figure" (1988: 35), Roth's therapists "do not marry their patients or have incestuous affairs with them" (Berman 1985: 239), instead they "maintain a proper distance from their patients, follow the rules of their profession, and avoid subverting their position into an instrument of evil power" (Berman 1985: 240). Roth has commented himself that his fictional psychoanalyst "hasn't been much of a character in the conventional novelistic sense," but rather like "the priest discreetly hidden away in the confessional" (Roth 1975: 82).

Yet, this holds true only up until his later work, My Life as a Man (1974), in which Dr. Spielvogel returns as an analyst publishing an anonymized account of his patient Tarnopol in the American Forum for Psychoanalytic Studies. Tarnopol is infuriated, as his identity-given that he is a published author and has recently written in the New Yorker about the same incident-can easily be discovered. Tarnopol confronts Dr. Spielvogel about this breach of confidentiality, highlighting that as a therapist he is bound "by ethical considerations" and should have asked for the patient's permission (Roth 1974: 250). Dr. Spielvogel, however, has no ethical qualms about having published the essay. He refuses to see this as a professional mistake, claiming that "none of us could write such papers, none of us could share our findings with one another, if we had to rely upon the permission or the approval of our patients in order to publish" (Roth 1974: 251). The quarrel almost leads to the termination of therapy, but Tarnopol ultimately decides that the bene- 
fits of therapy outweigh the harm of Dr. Spielvogel's publication, concluding that Dr. Spielvogel may be "a lousy analyst and a good therapist" (Roth 1974: 257). And yet, Tarnopol's confidence in his therapist has been destroyed. The basic trust between patient and therapist is lost, as Tarnopol can never quite forget that he "had been ill-used by him [Spielvogel]" (Roth 1974: 221).

\section{Sexual and Nonsexual Boundary Crossings and Violations}

Literary therapists frequently expose unprofessional behavior, which is uniformly grounded in their transgressing and violating of boundaries, the maintaining of which is recognized as fundamental to establishing trust in the therapeutic relationship (Gutheil and Gabbard 1993). Among them is Dr. Tamkin, the fraudulent psychologist/psychiatrist (he is referred to as both) in Saul Bellow's Seize the Day (1956). Dr. Tamkin, whose professional credentials are never confirmed, offers counseling to Tommy Wilhelm, who faces the breakdown of his marriage, the loss of his job, and a resulting financial ruin. From first meeting Dr. Tamkin, Tommy is concerned with the question: "could he trust Tamkin could he?" (Bellow 1977: 64). That Dr. Tamkin is disrespectful of boundaries already becomes apparent when he explicitly refers to "ethical reasons" when telling Tommy that he cannot disclose details about his other patients; yet he goes ahead and tells him all these details (Bellow 1977: 74). Dr. Tamkin ventures further into harmful boundary violations, when he starts advising Tommy to invest in the stock market, which ultimately causes Tommy to lose his money, after which Dr. Tamkin disappears.

Among the depictions of transgressions generally, the motif of the therapist engaging in a sexual relationship with a patient is probably the most frequently accounted for in literary depictions of psychotherapy. Notable examples include the half-American psychoanalyst Palmer Anderson in Iris Murdoch's novel A Severed Head (1961). Anderson, a seemingly "complete and successful human being," has the reputation of being a "modern magician" dividing his time between patients in London and Cambridge where "he lent his ear to neurotic undergraduates" (Murdoch 1961: 24). Palmer not only starts an affair with Antonia, the protagonist's wife, but as it turns out, also entertains an incestuous relationship with his half-sister. The theme of the psychiatrist/psychotherapist entertaining sexual relationships with a patient also appears parenthetically in Doris Lessing's œuvre. Even if Anna Wulf, Lessing's alter ego in the Golden Notebook (1962), has no extra-analytic relationship with her current therapist Mrs. Marks, she has an ex-lover Michel, who used to be her psychiatrist. Likewise, Ella-a fictional creation of Anna-also has an affair with her psychiatrist, Dr. Paul Tanner. Esther Greenwood, Sylvia Plath's alter ego in The Bell Jar (1963) also refers to the theme: When Esther first meets her therapist Doctor Gordon, she is surprised that he is "young and good-looking" (Plath 1963: 136). As a result, Esther "could see right away he was conceited" (Plath 1963: 136). Even though no actual transgression takes place, Esther describes being on guard throughout her session, as she actively fears that it will (Plath 1963: 138). 
While sexual affairs are predominantly referred to en passant, F. Scott Fitzgerald's Tender is the Night (1934) exemplifies the detrimental effects of substantial and multiple boundary violations, which are explored as ultimately unsolvable ethical conflicts. The novel chronicles the decline of the promising Oxford-educated psychiatrist Dick Diver. Diver, the author of a book entitled A Psychology for Psychiatrists, has the explicit ambition "to be a good psychologist - maybe the greatest one that ever lived" (Fitzgerald 2012: 151). Yet, various boundary violations, such as Diver's alcoholism (he examines a patient reeking of alcohol), his violence, and his confession that he never had a professional calling but "got to be a psychiatrist because there was a girl at St Hilda's at Oxford that went to the same lectures" (Fitzgerald 2012: 159), highlight that his aspirations collide with the ethical framework of his profession.

While working at a Swiss asylum Diver's professional interest in his schizophrenic patient Nicole Warren leads Warren to fall in love with him, which, in turn, seems to facilitate her recovery. Even if Diver is not made to "face ethics hearings and professional sanctions for his involvement with a patient" (Gutheil and Brodsky 2008: 9), his colleague Dohmler reminds him that this "is a professional situation" (Fitzgerald 2012: 161), and urges Dick to terminate the relationship. Instead, Diver marries Warren and when asked to take a leave for a combination of reasons, he feels partly relieved as "he had long felt the ethics of his profession dissolving into a lifeless mass" (Fitzgerald 2012: 288). His marriage, however, is not a happy one: Nicole relapses and Diver's "self-protective professional detachment" (Fitzgerald 2012: 193) toward her turns into complete indifference.

Tender is the Night exemplifies the complexities of sexual boundary violations, because Diver's involvement with Warren is from its start sustained by the fact that Warren seems to benefit therapeutically from their relationship. Moreover, the novel also highlights that however professionally detached the therapist claims to be, s/he is always also emotionally vulnerable (an "open wound" [Fitzgerald 2012: 193]). Diver plans to marry Warren because, as his colleague and friend Franz summarizes, he wants to "devote half of [his] your life to being a doctor and nurse" (Fitzgerald 2012: 162), which illustrates that caring for Warren ultimately also leads to a neglect of the self for the therapist.

\section{Professionalism and Informed Consent}

Within the corpus of literary depictions of psychotherapy, the Algerian-born, French writer Marie Cardinal's The Words to Say It (1976) and its "celebration of the analytic process" occupies a special place (Fallaize 1993: 31). While Roth's characters often experience relief through therapy, Cardinal's protagonist is shown to fully recover from her mental breakdown through analysis. The protagonist's unnamed therapist, described as a "little man" (1984: 3) and always "very distant" (1984: 2), remains largely absent from the text, merely referred to as an attentive listener who unwaveringly adheres to the rules of his profession. By negotiating both the beginning and end of therapy, the analyst makes his patient "accept adult responsibility for her therapy in the form of payment, which obliges her to resume work" (Fust 1999: 48). He also explicitly states that it is his 
"duty" to warn her about the risks of psychoanalysis and he explains what time and money commitment it entails (Cardinal 1984: 26). Cardinal's protagonist feels that the therapist's plain language and clear explanations allow her to feel "like a person capable of assuming responsibilities" (Cardinal 1984: 26). This informative discussion through which the therapist makes the patient understand the purpose, risks, and rules of therapy may thereby be seen as a form of informed consent, as the protagonist's "consent to this condition marks a first step toward taking charge of her life; in this way he actually empowers her" (Fust 1999: 48).

In the preface to The Words to Say It, Bruno Bettelheim describes the text as the "best account of psychoanalysis as seen and experienced by the patient," almost idealizing the analyst, who acted as a "compassionate guide who possessed the requisite wisdom" which facilitated the patient's "self-discovery" (Cardinal 1984: viii-ix). The complete absence of ethical conflicts in Cardinal's narrative of a life-changing therapeutic experience must be acknowledged and may even function as an example of how effective psychotherapy can be if it is shaped by professional practice as part of which the therapist is respectful of ethical obligations. Yet, the book also highlights that literary depictions of psychotherapy are informed by the therapeutic cultures in which they are conceived. The Words to Say It, as well as its reception, also mirrors the continuing stronghold of psychoanalysis in France (De Mijolla 2012) and exposes a specifically French psychoanalytic culture in which psychoanalysis continues to play an important, and perhaps uncritically accepted, role that may also be oblivious to specific ethical problems both in psychiatry and psychotherapy (Botbol and Gourbil 2018).

\section{Anti-Freudianism and Anti-Psychiatry}

Vladimir Nabokov is the author so well-known for relentlessly ridiculing and opposing Freudianism, that his view has been described as "the grandest and most extravagant contempt for psychoanalysis known in modern literature" (Green 1988: 1). Psychiatrists/ psychotherapists appear frequently in Nabokov's works; they are incompetent and expose grave ethical misconduct. Nabokov may have associated Freud with a number of different things he opposed, such as Bolshevism (de la Durantye 2005: 61), but he also explicitly critiqued the ethical views of psychoanalysis. In an interview in Strong Opinions, he claims that "the Freudian faith leads to dangerous ethical consequences, such as when a filthy murderer with the brain of a tapeworm is given a lighter sentence because his mother spanked him too much or too little - it works both ways" (Nabokov 1973: 116). Nabokov most famously parodies the determinist causality he views as ethically dangerous in Lolita (1955) and the ways in which Humbert anticipates how a psychoanalyst would read his transgressions, thereby "out-psycholog[izing] the most orthodox Freudian" (Berman 1985: 226).

Another example of anti-Freudianism can be found in Mario Vargas Llosa's Aunt Julia and the Scriptwriter (1977), where the protagonist, when starting psychoanalytic therapy, is told to stretch out on the couch "not because I believe in Freudian sanctimony, but be- 
cause I want you to feel comfortable" (Llosa 1995: 179). The therapist, Dr. Acémila, "a witch, a satanist, a corruptress of the corrupted, a madwoman" (Llosa 1995: 179), also explicitly tells her patient not to dwell on his past, informing him bluntly: "I shall not castrate you of your problem. I shall teach you to love it, to feel as proud of it as Cervantes of his useless arm or Beethoven of his deafness" (Llosa 1995: 180). As a result, the patient feels severely harmed and like "the victim of a psychic ambush" when leaving his therapist's office (Llosa 1995: 182).

While this reversal of roles between patient and therapist is grounded in Llosa's magic realism and his ironic and subversive celebration of the ambiguities of psychological reality, Doris Lessing also takes up this topos as part of a more general critique of the ethics of psychiatry and psychotherapy. A number of Lessing's novels, such as The Golden Notebook (1962) and The Four-Gated City (1969), have been described as "antipsychiatric" (Vlastos 1976), thereby stressing the similarities between her work and that of R. D. Laing. In The Golden Notebook, therapists are characterized as having "a scandalous familiarity with everything amoral," and yet being "traditional, rooted, conservative" (Lessing 2013: 26). Anna Wulf's therapist, Mrs. Marks, called "Mother Sugar," is even described as "uttering commonplaces in her capacity as witch-doctor she would have been ashamed of if she were with friends and not in the consulting room" (Lessing 2013: 76). But despite Lessing's fundamental skepticism regarding therapy and the overall dubious ethics and professional expertise of her therapists, her therapists are also often empathetic and helpful, yet "not through the art of psychotherapy, the validity of which Lessing rejects, but through the act of friendship" (Berman 1985: 180).

\section{Conclusion}

In her study of the therapeutic benefits of reading fiction, Josie Billington has emphasized that literature offers a privileged mode to explore "the inner life" of experience (2016: 92). In a similar vein, literary depictions of psychotherapy, by virtue of not aiming to demonstrate specific principles of the ethics of psychotherapy, may be said to provide valuable insights into the moral worlds and imaginations of therapists and patients generally, as well as into the lived experience of ethical conflicts emerging in psychotherapeutic practice specifically. Exploring the literary portrayal of psychotherapy allows readers to engage with specific nuances of these often unsolvable ethical conflicts, but also to question, for example, what the conflation of psychotherapy/psychiatry or the vagueness regarding specific schools means for psychotherapy ethics. It is noteworthy that in this cursory overview of the literary documenting of psychotherapy ethics, only a few instances stand out in which the therapist is depicted as caring and professional. In the majority of examples, psychotherapists are portrayed as incompetent and manipulative characters engaging in unethical, often harmful behavior. While the obscure-seeming lengthy and private relationship between therapist and patient certainly lends itself to a literary exploitation that focuses on transgressions of various kinds, the almost exclusive emphasis on these features also speaks to a wider social phenomenon. It has been claimed, for example, that psychiatry and psychotherapy have never enjoyed the "respect and social 
prestige of other medical specialties," as a result of which the World Psychiatric Association has itself published guidance on how to address the stigmatization of the field (Hopson 2014: 175). This negative public image is connected to a variety of reasons, such as the unclear role of scientific evidence in psychotherapy, the shifting categories and stigma of mental illness, as well as being more generally informed by the repercussions of the history of psychiatry with its long list of questionable treatments carried out on vulnerable patients at the mercy of their therapists (Hopson 2014: 178). Even if psychotherapy ethics is an often merely marginal topic in some of the textual examples analyzed here, these literary depictions of psychotherapy and psychotherapists can be seen as the mouthpiece of this negative image. By sensitizing readers to the culture-specific contextualization of ethical conflicts in psychotherapy, as well as by calling for an engagement with the wider societal impact of the literary image of psychotherapy and psychotherapists, these texts constitute an indubitably important addition to an ethics of psychotherapy curriculum.

\section{References}

\section{Primary Sources}

Bellow, S. (1977 [1956]). Seize the Day. New York: Avon Books.

Cardinal, M. (1984 [1976]). The Words to Say It (trans. P. Goodheart; Preface and Afterword by B. Bettelheim). Cambridge, MA: VanVactor \& Goodheart.

Fitzgerald, F. S. (2012 [1934]). Tender Is the Night. Cambridge: Cambridge University Press.

Greenberg, J. (1964). I Never Promised You a Rosegarden. New York: Penguin.

Kohler, S. (2014). Dreaming for Freud: A Novel. London: Penguin.

Lessing, D. (1969). The Four-Gated City. London: MacGibbon \& Kee.

Lessing, D. (2013 [1962]). The Golden Notebook. London: Fourth Estate.

Llosa, M. V. (1995 [1977]). Aunt Julia and the Scriptwriter. London: Penguin.

Murdoch, I. (1961). A Severed Head. London: Chatto \& Windus.

Nabokov, V. (1973). Strong Opinions. New York: McGraw-Hill.

Nabokov, V. (2000 [1955]). Lolita. London: Penguin.

Plath, S. (1963). The Bell Jar. London: Faber and Faber.

Roth, P. (1969). Portnoy's Complaint. New York: Penguin/Random House.

Roth, P. (1974). My Life as a Man. New York: Holt, Rinehart \& Winston. 
Roth, P. (1975). Reading Myself and Others. New York: Farrar, Straus \& Giroux.

Saks, E. R. (2007). The Center Cannot Hold: A Memoir of my Schizophrenia. London: Virago Press.

Stone, I. (1971). Passions of the Mind: A Biographical Novel of Sigmund Freud. New York: Doubleday.

Svevo, I. (2003 [1923]). Zeno’s Conscience (trans. W. Weaver). London: Vintage.

Yalom, I. D. (1989). Love's Executioner: And Other Tales of Psychotherapy. New York: Basic Books.

Yalom, I. D. (1992). When Nietzsche Wept. New York: Basic Books.

\section{Secondary Sources}

Berman, J. (1985). The Talking Cure: Literary Representations of Psychoanalysis. New York and London: New York University Press.

Berman, J. (2019). Writing the Talking Cure: Irvin D. Yalom and the Literature of Psychotherapy. Albany, NY: SUNY Press.

Billington, J. (2016). Is Literature Healthy? Oxford: Oxford University Press.

Botbol, M. and Gourbil, A. (2018). “The Place of Psychoanalysis in French Psychiatry.” BJPsych International 15: 3-5.

Charon, R. (2001). "Narrative Medicine: A Model for Empathy, Reflection, Profession, and Trust.” JAMA 286: 1897-1902.

De la Durantaye, L. (2005). "Vladimir Nabokov and Sigmund Freud, or a Particular Problem." American Imago 62: 59-73.

De Mijolla, A. (2012). La France et Freud. Paris: Presses Universitaires de France.

Fallaize, E. (1993). French Women's Writing: Recent Fiction. New York: Palgrave Macmillan.

Ffytche, M. (2010). "The Modernist Road to the Unconscious." In The Oxford Handbook of Modernisms (ed. P. Brooker, A. Gasiorek, D. Longworth, and A. Thacker, pp. 410-428). Oxford: Oxford University Press.

Freud, S. (1964 [1913]). "On Beginning the Treatment (Further Recommendations on the Technique of Psycho-Analysis I)." In The Standard Edition of the Complete Psychological Works of Sigmund Freud (Volume 12) (ed. J. Strachey, pp. 121-144). London: Hogarth Press. 
Fust, L. R. (1999). Just Talk: Narratives of Psychotherapy. Lexington: University Press of Kentucky.

Green, G. (1988). Freud and Nabokov. Lincoln: University of Nebraska Press.

Gutheil, T. G. and Brodsky, A. (2008). Preventing Boundary Violations in Clinical Practice. New York: Guilford Press.

Gutheil, T. G. and Gabbard, G. O. (1993). "The Concept of Boundaries in Clinical Practice: Theoretical and Risk-Management Dimensions." The American Journal of Psychiatry 150: 188-196.

Hawkins, A. H. (1993). Reconstructing Illness: Studies in Pathography. Lafayette, LA: Purdue University Press.

Hopson, J. (2014). "The Demonization of Psychiatrists in Fiction (and Why Real Psychiatrists Might Want to Do Something About It)." Psychiatric Bulletin 38: 175-179.

Lin, L., Stamm, K., and Christidis, P. (2015). Demographics of the U.S. Psychology Workforce: Findings from the American Community Survey. Washington, DC: American Psychological Association.

Marks, S. (2017). "Psychotherapy in Historical Perspective." History of the Human Sciences 30: 3-16.

Mosher, P. W. and Berman, J. (2015). Confidentiality and its Discontents: Dilemmas of Privacy in Psychotherapy. New York: Fordham University Press.

Newton, A. Z. (1997). Narrative Ethics. Cambridge, MA: Harvard University Press.

Nussbaum, M. (1990). Love's Knowledge: Essays on Philosophy and Literature. Oxford: Oxford University Press.

Radden, J. and Varga, S. (2013). "The Epistemological Value of Depression Memoirs: A Meta-Analysis." In The Oxford Handbook of Philosophy and Psychiatry (ed. K. W. M. Fulford, M. Davies, and G. Graham, pp. 99-115). Oxford: Oxford University Press.

Shechner, M. (2003). Up Society's Ass, Copper: Rereading Philip Roth. Madison: University of Wisconsin Press.

Surprenant, C. (2006). "Freud and Psychoanalysis." In Literary Theory and Criticism: An Oxford Guide (ed. P. Waugh, pp. 199-211). Oxford: Oxford University Press.

Trilling, L. (1940). “The Legacy of Sigmund Freud, Part 2: Literary and Aesthetic.” Kenyon Review 2: 152-173.

Tucker, M. (1988). "The Shape of Exile in Philip Roth, or the Part is Always Apart." In Rereading Philip Roth (ed. A. Z. Milbauer and D. G. Watson, pp. 33-49). London: Macmillan. 
Vlastos, M. (1976). "Doris Lessing and R. D. Laing: Psychopolitics and Prophecy." PMLA 91: 245-258.

\section{Notes:}

(1.) Given that intrapsychic conflicts constitute the subject matter of both literature and psychoanalysis, this particular affinity was supposedly already accounted for by Freud, who, when praised as the "discoverer of the unconscious," responded that the poets and philosophers had discovered it before him, but that he had merely produced "the scientific method by which the unconscious can be studied" (Trilling 1940: 152). Particular cultural and conceptual parallels between psychoanalysis, "the talking cure" and literature, as well as literary analysis, have been remarked upon since Freud, even if some modernist writers themselves were already critical of Freudianism (Ffytche 2010: 410). Since the reflection on ethical conflicts is a constitutive part of Freud's own writing, early psychoanalytic approaches to literature, as well as the development of psychoanalytic literary criticism and the reading of Freud's case studies as literature, all highlight the multiple forms in which the affinity between literature and psychoanalysis has considered the ethical views raised by Freud (Surprenant 2006: 200).

(2.) As a result, this chapter does not take into consideration the recent "boom in autobiographical writing about mental illness" (Radden and Varga 2013: 100). While psychotherapy may be frequently alluded to in these often bestselling memoirs, such as for example Greenberg's semi-autobiographical I Never Promised You a Rosegarden (1964) or Saks's The Center Cannot Hold: A Memoir of my Schizophrenia (2007), the main focus of these works is the exploration of the experience of mental illness rather than an investigation of the ethical challenges created by psychotherapy.

(3.) The "psychotherapy tale" is a genre primarily associated with the writing of the existential-humanistic psychotherapist Irvin D. Yalom. Yalom-both in his fiction and nonfiction-engages with many ethical conflicts arising in the therapeutic relationship or as part of group therapies, and his writing is explicitly "designed to illuminate different aspects of psychotherapy for young therapists" (Berman 2019: xiv).

\section{Anna Magdalena Elsner}

Institute of Biomedical Ethics and History of Medicine, University of Zurich 